\title{
Método para pesquisa de tendências: uma revisão do modelo Futuro do Presente
}

Trend forecasting method: a review on the model Futuro do Presente

\section{Amanda Queiroz Campos \\ Mestre em Design (Programa de Pós-Graduação em Design/UFSC) amandaqc88@gmail.com \\ Sandra Regina Rech}




\section{Método para pesquisa de tendências: uma revisão do modelo Futuro do Presente}

Trend forecasting method: a review on the model Futuro do Presente

\section{Amanda Queiroz Campos e Sandra Regina Rech}

\section{Resumo}

Este estudo apresenta, de forma revisada, o método de pesquisa de tendências desenvolvido e aplicado pelo projeto FPLab - Futuro do Presente. O desenho metodológico proposto, inicialmente como modelo conceitual, é de natureza qualitativa e envolve processos indutivos e dedutivos, baseando em pressupostos e abordagens das Ciências Humanas. De modo específico, a principal referência para este método é a Teoria Fundamentada nos Dados, de Glaser e Strauss (1967), que define a necessidade de as hipóteses surgirem dos dados e rejeita a ida à campo para a confirmação, ou rejeição, de hipóteses formuladas anteriormente à coleta de dados. O investimento na Teoria Fundamentada como referência de pesquisa também influencia as etapas de análise - codificação - dos dados, uma vez que é o procedimento mais importante da pesquisa de tendências. $O$ método foi desenvolvido para o projeto de pesquisa em questão, mas pode, feitos os devidos ajustes, ser aplicado em outros contextos para fins de pesquisa prospectiva.

Palavras- chave: pesquisa de tendências; metodologia; moda

\begin{abstract}
This study presents a review on the trend forecasting method developed for and applied by the FPLab research project. The method initially proposed as a conceptual model is of qualitative nature, involves inductive and deductive procedures, and relies on Human Sciences approaches and premises. More specifically, the main reference to the method is Grounded Theory of Glaser and Strauss (1967), which defines the need for hypothesis to arise from the data and rejects the procedures of going to the field merely to confirm or reject hypothesis that where formulated priory to the field experience. The investment in such theory as research reference also influences the stages of data analysis - coding -, considered the most important phase of trend analysis forecasting. We have developed this method to the researchconcerned group; however, one may apply it in other contexts with the goal of prospective research with the necessary adjustments.
\end{abstract}

Keywords: Trends Forecasting, methodology;Fashion 


\section{Introdução}

A pesquisa de tendências tem alterado sua abrangência e formatos no decorrer deste século XXI. Atuando de modo estratégico, não apenas o uso das tendências, mas a própria pesquisa de tendências tem se tornado assunto relevante na sociedade contemporânea. Claramente, os estudos sobre o futuro interessam à humanidade há milênios e são presentes por toda a história, todavia, recentemente, o papel central das tendências - principalmente tendências de ampla abrangência (macrotendências) e de comportamento - observa crescimento e valorização no mercado. Isso pode ser notado, por exemplo, no crescimento do número de empresas que dedicam-se à busca de tendências do comportamento do consumidor no mundo e, localmente, no Brasil. Igualmente, cresce a influência dessas empresas. "A disseminação da indústria de previsão de tendências, e sua trajetória utilizada meramente para aconselhamento do estilo da moda, torna-se política e de efeito sobre os grandes operadores da sociedade" (PETERMANN, 2014, p.1) ${ }^{1}$.

Os estudos de tendências envolvem pesquisar o presente e traçar planos, visões e conjunturas sobre o futuro (CAMPOS, 2013). De acordo com Uerz (2006) e van der Duin (2007) apud Petermann (2014), os estudos do futuro surgiram no contexto após a Segunda Guerra Mundial e tinham como objetivo produzir conteúdo sobre o futuro em diversas áreas tentando responder ao questionamento “o que virá a seguir?”. Os especialistas tinham foco generalista ou específico, por exemplo, nas áreas de economia ou moda.

No campo da moda, especificamente, as empresas de pesquisa de tendência surgiram com o objetivo principal de organizar oferta e demanda, além de criar um calendário organizador para a indústria de moda. Atualmente, tradicionais empresas de pesquisa de tendência de moda ampliam o foco de sua atuação e oferecem consultoria

\footnotetext{
${ }^{1}$ The dissemination of the trend forecasting industry and its trajectory from being merely used for fashion style advice to becoming political and having effect on major operators of society" (PETERMANN, 2014, p.1).
} 
de posicionamento, gestão de marca e novos mercados, atuando de modo semelhante ao proposto pelo pesquisador de tendências alemão Matthias Horx, como ciência universal.

Para traçar direcionamentos para produtos, serviços e marcas no futuro, empresas e pesquisadores dessa "ciência universal" investem em especialistas de diversas áreas e aplicam metodologias próprias baseadas em evidências, em pesquisas em triangulação (RAYMOND, 2010) ou coolhunting (RIEZU, 2009). Sendo que a metodologia parece ser o principal parâmetro para o estabelecimento de confiança e credibilidade à pesquisa de tendências, este artigo tem como objetivo apresentar a metodologia desenvolvida para o projeto de Pesquisa Futuro do Presente Lab durante o ano de 2009 e aprimorada desde então em publicações (CAMPOS, 2010; CAMPOS, RECH, 2010; CAMPOS, PERASSI, RECH, 2012; RECH, 2013; RECH, 2015) apoiada na prática de pesquisa em grupo e em corpo teórico crescente e em renovação.

\section{Pressupostos para o desenvolvimento da metodologia}

A partir de pesquisas bibliográficas em Ciências Humanas e Ciências Sociais Aplicadas, e com base em feedbacks de testes realizados durante o processo de desenvolvimento de métodos de pesquisa de tendência para moda, produziu-se um modelo conceitual para a prospecção de tendências de moda. O projeto de pesquisa FPLab se dedica à investigação dos campos social e cultural, intermediados pela internet para a coleta e comunicação de resultados com foco no futuro, tendo como objetivo contribuir no processo de desenvolvimento de produtos e serviços.

$\mathrm{O}$ referencial teórico que baseia os estudos de pesquisa de tendências (CALDAS, 2004; VINCENT-RICARD, 2008; VEJLGAARD, 2008; SANTOS, 2013; MONÇORES, 2013; McCRACKEN, 2011; LINDKVIST, 2010; entre outros) sugere a utilização de técnicas e abordagens de áreas como antropologia e sociologia como suporte primordial para a metodologia. Assim sendo, o desenho metodológico proposto baseia-se em métodos e técnicas qualitativos e indutivos. Além disso, a coleta de dados investe no monitoramento de informações de diversos campos do conhecimento; tais como: política, economia, cultura, arte, sociedade, tecnologia, etc. A ampla gama de influências pesquisadas enrique o escopo da pesquisa e fornece variabilidade de dados e, por consequência, de resultados. A análise dos dados é o que exerce papel central e 
possibilita orientações transversais - já que ultrapassam áreas e conhecimentos específicos e podem ser direcionadas aos mais variados nichos e setores do mercado.

O cerne da pesquisa consiste na análise e interpretação dos dados. De acordo com Vicentini e Castilho (2008), na atualidade caracterizada pela velocidade e disponibilidade da informação, torna-se a principal dificuldade não a identificação e avaliação das fontes de dados, mas sua síntese e organização. Assim, a utilização da metodologia auxilia um suposto distanciamento que auxiliaria pesquisadores iniciantes a lidar com os dados de modo mais objetivo e organizado. Apesar das abordagens mais recentes em ciências humanas valorizarem a pesquisa subjetiva, neste caso mantêm-se uma lógica mais tradicional por dois principais motivos. O primeiro deles dá-se pela não formação em Ciências Humanas dos alunos que participam do projeto, além da pouca ou nenhuma experiência com pesquisa. A segunda justificativa é a necessidade de aplicabilidade dos resultados das pesquisas, uma vez que o trabalho é desenvolvido com o objetivo de gerar direcionamentos de produtos e serviços para cenários futuros. Logo, a metodologia consiste de etapas e ações organizadas e do controle do grupo de pesquisadores de modo a dirigir a organização, validade e utilidade dos resultados. Todavia, a proposta sugerida foge de ferramentas, cronogramas ou sequências de passos exatos; assim, prima-se pela flexibilidade, indicando uma trajetória adaptável e maleável a diferentes aplicações.

\section{Modelo conceitual proposto}

A investigação é organizada em quatro principais etapas: (1) o preparo da pesquisa, seleção de fontes e organização do calendário; (2) a coleta de dados; (3) a análise de dados; e (4) a delimitação de teorias, ou seja, o fechamento das hipóteses de tendências e comunicação dos resultados. As etapas de pesquisa foram organizadas visualmente na Figura 1. 
Figura 1: Modelo conceitual proposto para a pesquisa prospectiva.

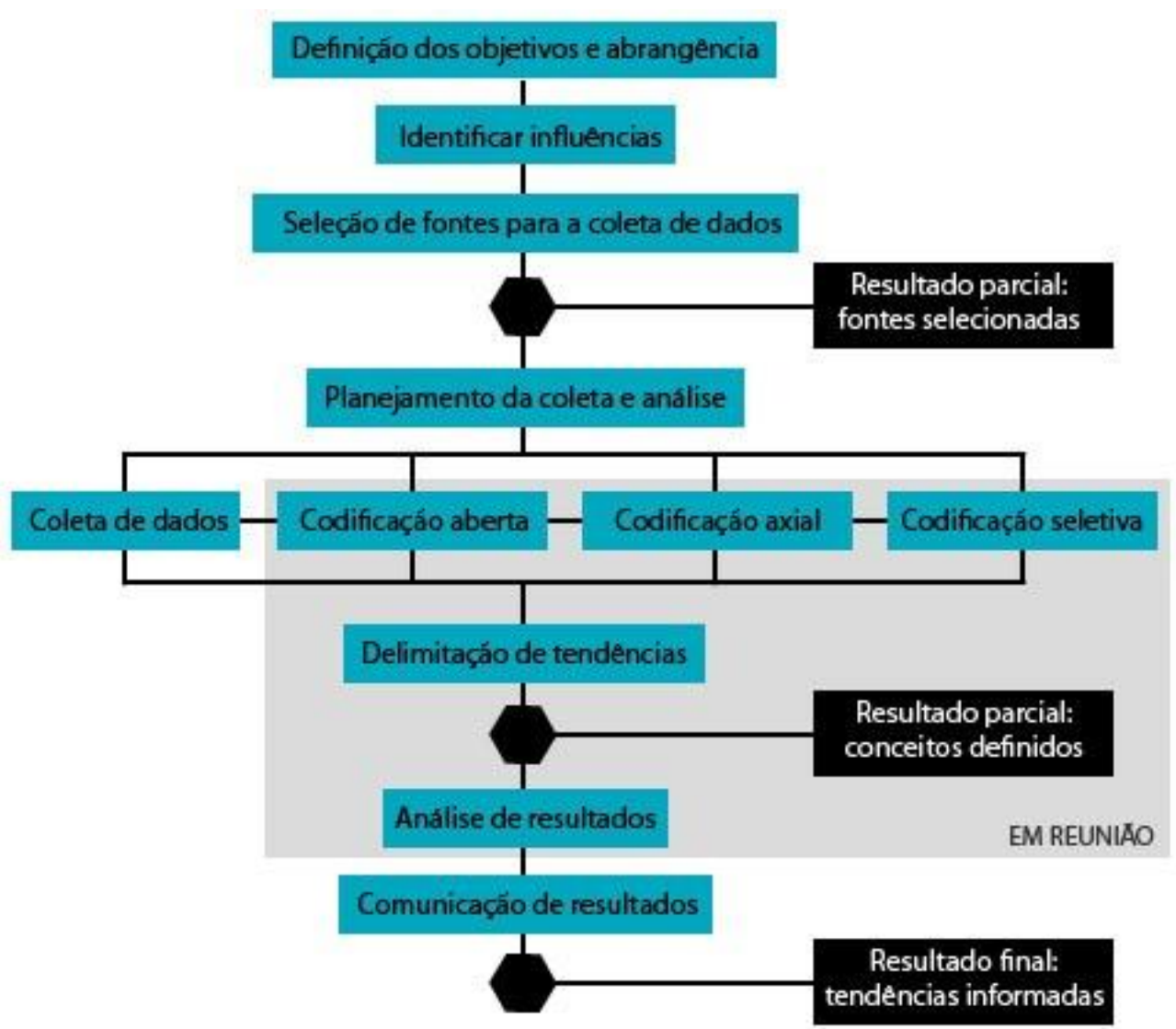

Fonte: Autoras (desenvolvido para o projeto de pesquisa FPLab - CEART/UDESC)

A primeira etapa do modelo consiste no planejamento da pesquisa. Neste momento, diversos fatores devem ser avaliados anteriormente ao início do trabalho. Deste modo, planeja-se não apenas a pesquisa em si, mas também o tipo de resultado esperado. Back (2008) sugere como ferramentas válidas para um bom aproveitamento desta etapa: reuniões, consulta com especialistas, técnicas e procedimentos de análise financeira e softwares de gestão de projetos e recursos humanos (Fig.2). 
Figura 2: Detalhamento da fase de planejamento

\begin{tabular}{|l|l|}
\hline \multicolumn{1}{|c|}{ Atividade } & \multicolumn{1}{|c|}{ Tarefa } \\
\hline Definiçáo dos objetivos da pesquisa & $\begin{array}{l}\text { Definir quais as intenḉes com a pes- } \\
\text { quisa de tendencias, registrar objetivos }\end{array}$ \\
\hline Definiçáo da abrangência da pesquisa & $\begin{array}{l}\text { Definir a abrangéncia pretendida: } \\
\text { macro ou microtendencias }\end{array}$ \\
\hline Verificaçáo da viabilidade da pesquisa & $\begin{array}{l}\text { Estimar, verificar e otimizar a disponibi- } \\
\text { lidade de recursos }\end{array}$ \\
\hline Definiçáo de cronograma & $\begin{array}{l}\text { Planejar atividades e definir prazo e } \\
\text { cronograma }\end{array}$ \\
\hline Definiçáo da equipe de trabalho & $\begin{array}{l}\text { Verificar competenciase interesses, se- } \\
\text { lecionar tarefas e responsabilidades }\end{array}$ \\
\hline
\end{tabular}

Fonte: Adaptado de Back (2008).

A metodologia proposta, e atualmente utilizada, considera a pesquisa em três grandes grupos de enfoque, intitulados categorias: (1) macrotendências, (2) comportamento e (3) setores de referência. Os setores de referência consistem em práticas inovadoras já realizadas por empresas e indústrias, material discursivo publicitário ou pesquisas específicas em tecnologia. A pesquisa desta categoria é fundamental, uma vez que reflete demandas consumidoras já latentes, ainda que expoentes; contudo a influência possibilita principalmente vislumbrar quais tecnologias e métodos já estão disponíveis, de modo a ajustar os direcionamentos de produtos de modo mais exato.

Após a definição dos escopos da pesquisa, as fontes de coleta de dados devem ser selecionadas. No escopo do projeto de pesquisa investiga-se essencialmente através da internet, pois, no atual contexto de convergência de mídia e sociedade de informação, considera-se que o material disponibilizado online de algum modo reverbera aspectos da vida social e cultural, constituindo o que autores denominam blogosfera. Ou seja, mapeiam-se principalmente conteúdos veiculados em blogs consoante diferentes áreas do conhecimento e mercado. No início do projeto foi organizada uma lista de blogs e sites para referência, que vem sendo atualizada pelas atuais bolsistas participantes ${ }^{2}$. Contudo, estas não se limitam aos sítios listados como referência, uma vez que a própria

${ }^{2}$ http://fplab.com.br/site/tendencias-2/mapa-da-mina/ 
dinâmica da rede - construída por hiperlinks - possibilita e incentiva a navegação livre entre páginas e referências.

A fase de pesquisa documental é formada pela coleta e análise de dados e implica, posteriormente, na delimitação de tendências. Esses processos envolvem o recolhimento de material para organização analítica e interpretativa. Tais práticas têm como objetivo identificar dentre todos os dados uma ou algumas categorias centrais que de algum modo justifiquem ou sumarizem os dados coletados, tendo como base a sociedade. Após a avaliação da hipótese de tendência, pode-se avaliá-la, através de procedimentos comparativos e de base quanti-qualitativa com outras categorias e com a mesma categoria ao decorrer do tempo.

Figura 3: Detalhamento da fase de coleta e codificação de dados

\begin{tabular}{|l|l|}
\hline \multicolumn{1}{|c|}{ Atividade } & \multicolumn{1}{|c|}{ Tarefa } \\
\hline Plano de síntese dos resultados & $\begin{array}{l}\text { Definir com base nos objetivos gerais definidos na fase de } \\
\text { planejamento a formatação e publicação dos resultados }\end{array}$ \\
\hline Síntese dos resultados & $\begin{array}{l}\text { Organizar as informações da fase de coleta e análise de } \\
\text { dados para comunicar as tendências delimitadas de mo- } \\
\text { do adequado ao público destinado }\end{array}$ \\
\hline
\end{tabular}

Fonte: Autoras

A etapa final (Fig. 3) refere-se aos resultados. Num primeiro momento, planejase a síntese das informações coletadas, levando em consideração os objetivos delineados durante a fase de planejamento da pesquisa. Posteriormente, parte-se para a síntese do resultado, momento no qual as tendências coletadas são configuradas em informação para serem comunicadas ao público interessado. No projeto, as tendências são comunicadas por meio de textos, exemplos (cases), painéis imagéticos, seminários e mapas conceituais.

O próximo item deste artigo aborda, de modo aprofundado, as principais etapas da pesquisa, ou seja, a fase de coleta de dados; a de análise e interpretação dos dados, correspondente às etapas de codificação aberta, axial e seletiva, e; a etapa de delimitação das tendências.

\subsection{Coleta de dados}

De acordo com Raymond (2010), uma das principais habilidades requerida para a pesquisa de tendências é o tato. Utilizando o termo em sentido figurado, o pesquisador 
inglês de tendências ilustra a pesquisa prospectiva como "braile cultural". Ou seja, envolve sentir sutilmente aspectos cotidianos que, mesmo podendo passar desapercebidos ou desinteressantes para alguns, são marcantes e relevantes - em alusão ao próprio relevo dos textos em braile.

A pesquisa de tendências não consiste na observação do futuro, mas na pesquisa do presente por itens potencialmente virais que poderão infectar os horizontes da moda e do design no amanhã, aludindo às ideias de contágio e virulência (GLADWELL, 2009; RAYMOND, 2010; DAWKINS, 2007). A descoberta de quais serão as maiores tendências do futuro envolve processos indutivos e dedutivos; isto é, funciona como a montagem de um quebra-cabeça complexo, em que se combinam diversas peças do contemporâneo até que se forme um panorama plausível para o porvir.

A metodologia proposta baseia-se, principalmente, na Teoria Fundamentada dos Dados (GLASER, STRAUSS, 1967; STRAUSS, 1987; CORBIN, STRAUSS, 2008; SONEIRA, 2007). Apesar desta teoria utilizar majoritariamente entrevistas como técnica de coleta de dados, ela não exclui outras técnicas, entre elas: conversação informal, observação participante e não-participante, focus groups, análise documental e de literatura. A técnica de coleta de dados utilizada pelo projeto de pesquisa FPLab Futuro do Presente - consiste em na seleção de documentos da internet. Como proposto pela metodologia, e como característica central da pesquisa de tendências, a primeira leva de coleta de dados não é direcionada por uma hipótese, ou seja, diversos materiais e temas são coletados, em momento exploratório de campo.

Após essa primeira coleta, tem-se os primeiros processos de codificação, o que dirige e remodela o processo de recolhimento dos dados, com base nas informações já coletadas e nas hipóteses que se formam a partir dos dados durante as etapas de coleta e codificação. A coleta de dados acontece por etapas sucessivas. O discernimento de eleição de dados não é norteado por uma porção representativa em termos estatísticos, quantitativos, mas pela construção de um corpus baseado no conhecimento e na experiência provenientes dos dados.

É relevante frisar que o processo contínuo de coleta e análise de dados tem como foco o humano, "que é na realidade o primeiro motor dos complicados mecanismos aqui analisados” (BARCARO, 2008, p.156). As abordagens de pesquisa em Ciências Humanas concebem o ser humano como fator primordial. Num contexto mercadológico 
de aplicação da teoria, considerando o indivíduo enquanto consumidor e cliente, Francesco Morace (2009) - sociólogo e presidente da agência de pesquisa de tendência Future Concept Lab - pondera que cada vez mais os produtos e serviços devem ser modelados para este que é o protagonista do mercado.

De acordo com McCracken (2011), para criar produtos e serviços realmente inovadores, deve-se principalmente observar a cultura. E o bom observador é aquele que tem bom faro, considera detalhes do mundo à sua volta com interesse e observa com estranheza fatos cotidianos. Bons examinadores "são observadores perspicazes de pessoas, equipes, organizações, tecnologias - e tendências. Eles veem sutilezas e padrões" (KELLEY; LITTMAN, 2001, p.48). Muitas vezes, é o olhar incomum que revela algo novo, que, por muitos, pode passar desapercebido. É necessário que se despertem as antenas para a percepção da variedade infindável do humano e da cultura.

Além da compreensão e observação sistemática do ser humano e seu comportamento, atitude e implicações, deve-se atentar para um entendimento mais abrangente dos materiais coletados. É requerido levar em consideração o contexto geral de seu desenvolvimento e atuação; contexto no qual que as pessoas exercitam seus papéis enquanto atores sociais. Juntamente ao processo de coleta de dados, sugere-se a “observação sistemática” (MANN, 1979), que já envolve primeiros passos de análise e interpretação, ao constantemente perguntar: quem? quando? onde? como? e, principalmente, por quê?

\subsection{Análise de dados}

A análise de dados é considerada o processo mais difícil da pesquisa de tendências, pois envolve a filtragem e interpretação de todas as informações coletadas e, também, dos insights e ideias dos pesquisadores durante o processo de coleta de dados, o que abarca - em ambos os casos -aspectos extremamente subjetivos. A codificação ou análise é o procedimento através do qual os dados são conceitualizados, categorizados, hierarquizados e as relações entre os dados e as categorias são estabelecidas.

O procedimento analítico, neste momento iniciado, tem como objetivos: (1) construir a teoria; (2) dar ao processo científico o rigor metodológico necessário; (3) auxiliar o pesquisador a detectar os vieses da pesquisa; (4) desenvolver o fundamento, a densidade, a sensibilidade e a integração necessária para gerar uma teoria A análise de 
dados envolve a geração de conceitos através do processo da codificação aberta que representa as operações através das quais os dados são quebrados, conceitualizados e reconectados de novas maneiras (CORBIN, STRAUSS, 2008).

A codificação consiste em destrinchar os conceitos mais relevantes a partir da análise do material coletado (SONEIRA, 2007), para tal, é necessário ler e reler o material coletado, a fim de entender os desejos e impulsos escondidos atrás de cada informação, além do contexto de seu acontecimento. "Obtendo os dados, o investigador examina-os linha por linha e recorta as unidades de análise. Assim cada unidade de análise é nomeada com uma palavra ou sentença exprimindo o significado desta para o investigador" (CASSIANI, CALIBRI, PELÁ, 1996, p.80). A codificação é a parte central da análise dos dados e não consiste em mera associação de trechos e dados às categorias. O processo compreende, de modo holístico, absorventes e frequentes questionamentos e a oferta de respostas provisórias sobre o material coletado. As respostas provisórias serão conferidas e aperfeiçoadas através de novas coletas de dados e sucessivos procedimentos de codificação. Esta circularidade entre coleta e análise de dados é ilustrada pela figura 4.

Figura 4: A circularidade entre a coleta e a análise dos dados

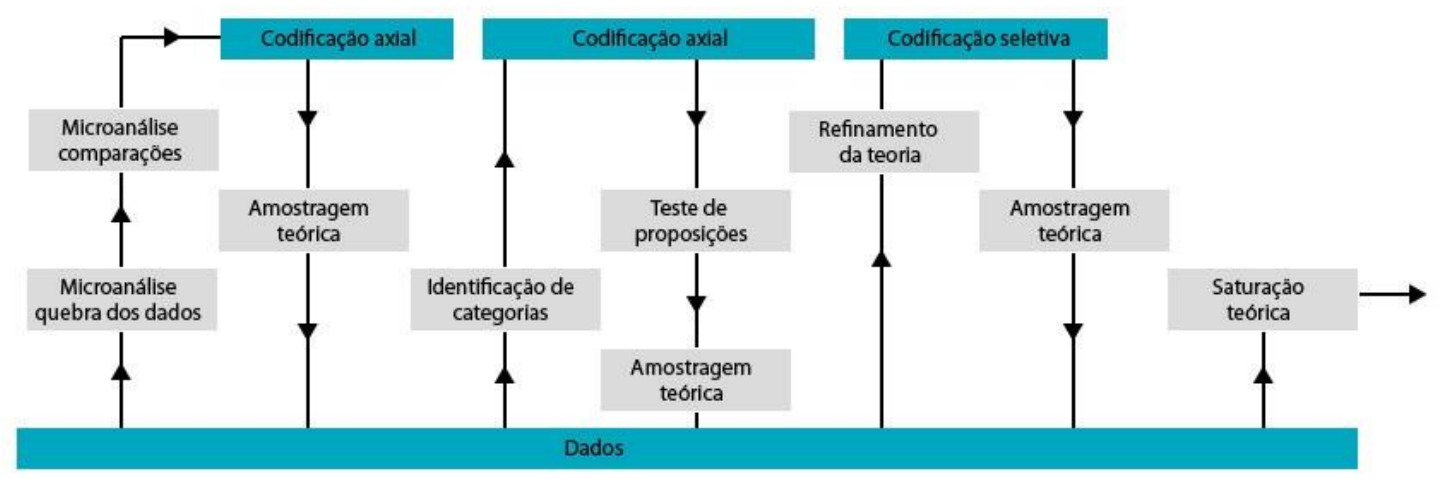

Fonte: adaptado de Bandeira-de-Mello e Cunha (2007, p. 253)

As etapas de codificação propostas por Glaser e Strauss (1967) são a codificação aberta, a codificação axial e a codificação seletiva. A primeira delas, codificação aberta ou open coding, consiste nos rompimentos, análises e conceituações. Durante este primeiro momento, os dados são analisados sem uma orientação clara, observando e ponderando todas as informações em um procedimento de "microanálise" dos dados. 
A codificação aberta também envolve a geração de conceitos que representem, esclareçam ou sintetizem o material coletado. Isso não apenas reduz a quantidade dos dados que o pesquisar precisará trabalhar, mas, ao mesmo tempo, fornece uma linguagem para que os dados sejam articulados.

A grande questão no processo de elaboração de conceitos não é precisamente caracterizar um dado, mas sim estabelecer seus limites estruturais, descobrir qual o conceito constitui mais adequadamente a circunstância. Posteriormente, os conceitos que pertencem a um mesmo tema ou universo serão agrupados em torno de uma categoria conceitual. A ruptura possibilita a identificação e agrupamento de informações, descontextualizando-as, ou seja, extraindo-as do texto ou contexto original para que mais tarde seja possível a organização de um novo texto contexto (recontextualização) e descobrir propriedades e dimensões ocultas do fenômeno em estudo (SONEIRA, 2007).

A segunda etapa de codificação é a codificação axial, ou axial coding. Nela as relações entre categorias são examinadas. Enquanto a codificação aberta fratura os dados em conceitos e categorias, a codificação axial volta a organizar os dados de modo diferente. Essa reconstrução em novas formas cria ou evidencia conexões entre dados e categoria, inclusive criando hierarquias através de subcategorias. Nesta etapa desenvolvem-se referências que buscarão identificar a temática central - ou mais abrangente - das tendências. O processo de codificação axial compara todos os dados e questiona a existência e permanência dos fenômenos observados durante processos de codificação aberta.

O processo de estabelecimento de relações entre conceitos e categorias recria padrões semelhantes a um holograma (Fig.5), no qual as partes e o todo constroem-se reciprocamente. Essa organização de conceitos e categorias consiste em um procedimento indutivo, onde as categorias já formadas são analisadas comparativamente, à luz dos novos dados, com o intuito de tentar identificar naquelas referentes as mais significativas. Esse processo reduz o número de categorias. $\mathrm{O}$ agrupamento de categorias acontece como modo de análise, já que, para a organização e hierarquia de categorias, integrações emergem e conexões tornam-se explícitas. Assim que as categorias começam a surgir, reunidas formam conjuntos mais gerais, mais abstratos, de avaliação das tendências. 
Figura 5: Exemplo de codificação axial

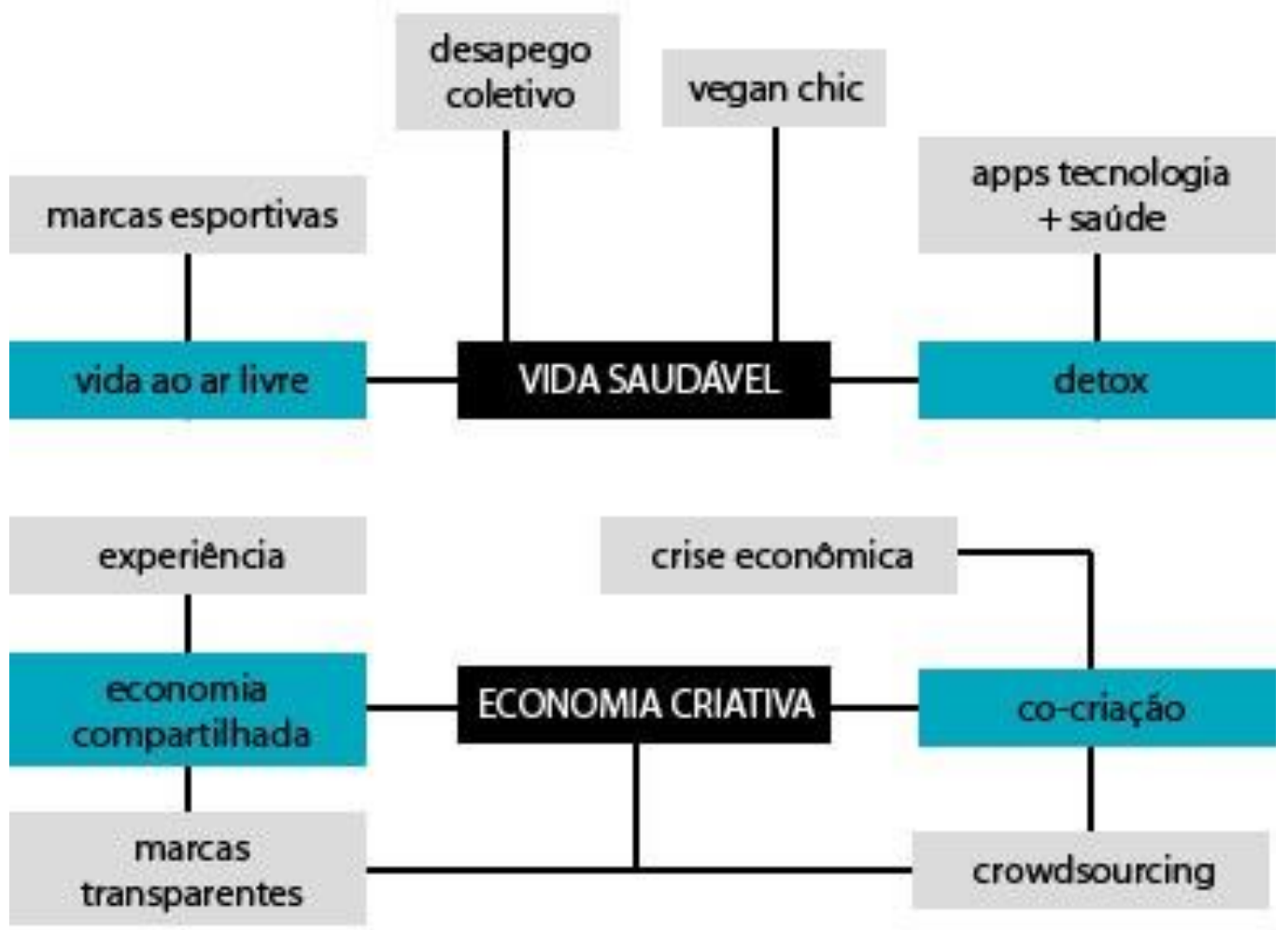

Fonte: Adaptado de FPLab ${ }^{3}$

De modo a auxiliar o processo de eleição da categoria central ou mais explicativa, teóricos desenvolveram o denominado modelo paradigmático (Fig.6); o qual auxilia na identificação do fenômeno - no presente caso, tendência - central, além de identificar as relações de causa ou influência, o contexto, as condições de intervenção e etc. Como as relações nem sempre são evidentes, o esquema torna-se útil para compreender o fenômeno. A proposta básica é permitir que o pesquisador pense sistematicamente sobre os dados e os relacione de modo complexo. O padrão fundamentalmente propõe conexões e atrelamentos. Sugere, igualmente, que se volte aos dados para validações, movendo-se entre o constante questionamento, a geração de hipóteses e a construção de comparações.

\footnotetext{
${ }^{3}$ Disponível em: http://fplab.com.br/site/portfolio/trend-book-3/
} 
Figura 6: O modelo paradigmático

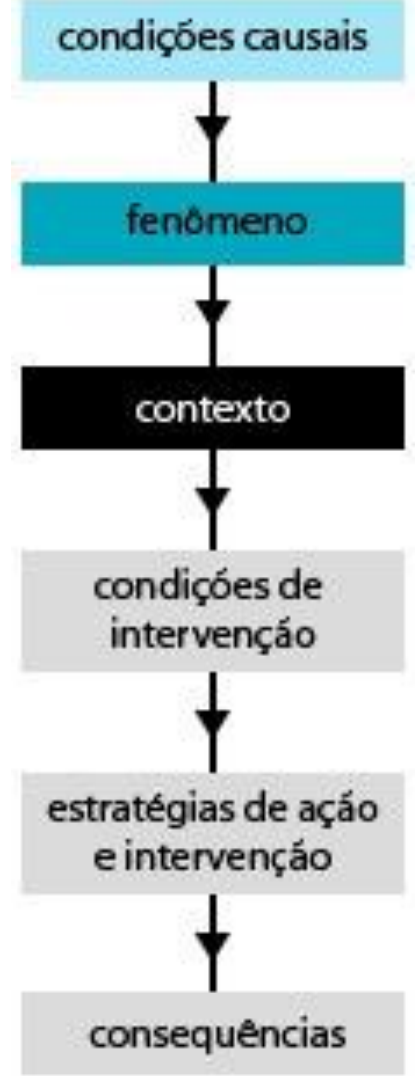

Fonte: Adaptado de Pandit (1996, p. 9)

A última etapa de codificação, a codificação seletiva (selective coding) envolve a integração das categorias que foram desenvolvidas. De acordo com Bandeira-deMello e Cunha (2007, p.253), essa primeira etapa da codificação "integra a teoria desenvolvida, examina possíveis incoerências, categorias com fraca fundamentação empírica ou relações não estáveis. O objetivo da integração é identificar a(s) categoria(s) central(is) da teoria, com a(s) qual(is) todas as outras estão relacionadas”.

A codificação seletiva dos dados é empregada de maneira não tão diferente da codificação axial, porém em nível mais abstrato. Por exemplo, neste momento as categorias devem ser relacionadas para que uma delas seja eleita como central, analisando os tópicos do paradigma. A categoria central deve permitir a integração de todos os dados recolhidos referentes a um mesmo fenômeno, ou pelo menos, o máximo deles. 
Também nesta fase da pesquisa é hora de validar as relações e complementá-las com dados adicionais, caso necessitem refinamento ou desenvolvimento. Autores consideram válido criar uma linha narrativa explicativa do fenômeno, resumindo-o em poucas frases (SONEIRA, 2007). Isto pode ser desafiador, uma vez que é necessário recortar e selecionar categorias e questões que realmente sejam relevantes para a elaboração um modelo representativo do fenômeno de modo a delimitar a teoria, ou no caso, a tendência.

\subsection{Delimitação da teoria}

A delimitação da teoria consiste na avaliação das hipóteses de tendências, por meio de comparação de semelhanças e divergências entre os conceitos e teorias. Uma lista elaborada por Strauss (apud SONEIRA, 2007) auxilia na avaliação da categoria eleita como central e na sua delimitação. Para o autor, a delimitação da teoria deve (1) relacionar-se com as demais categorias; (2) aparecer com frequência nos dados; (3) ter explicação lógica e convincente; (4) ser abstrata o bastante para que induza a uma teoria mais geral; (5) ser profunda e explicativa, e; (6) ser capaz de explicar o fenômeno em condições variadas.

Após delimitada, a teoria - tendência - deve passar por uma análise de abrangência, ou seja, considerar a possibilidade de replicação dos resultados. Assim, uma teoria pode ser substantiva ou formal. É substantiva quando se refere a uma mesma classe de grupos ou de casos e formal quando possíveis de comparação a nível conceitual amplo. No caso específico do projeto de pesquisa FPLab - Futuro do Presente -, as tendências delimitadas são comumente expandidas para o nível formal. Isto é, as tendências observadas têm suas possibilidades de generalização ampliadas, dilatando o alcance das prospecções a serem comunicadas.

A generalização não ocorre de modo aleatório, mas consiste em aproximações indutivas com base nos dados coletados e codificados. Glaser e Strauss (1967) apud Soneira (2007, p.159) apresentam o seguinte exemplo: Uma teoria substantiva que tem como categoria a perda social de moribundos, poderia ter o escopo ampliado de modo a estabelecer uma teoria formal ao ter como categoria "o valor social das pessoas". Por sua vez, a propriedade da categoria substantiva, "cálculo da perda social de acordo com as características aprendidas e aparentes do paciente", tornar-se-ia, na teoria formal, "o 
cálculo do valor social das pessoas, segundo as características aprendidas e aparentes". Por fim, enquanto na teoria substantiva as hipóteses seriam: (a) quanto maior for a perda social de um paciente terminal, melhor a sua atenção e (b) quanto maior for a perda social de um paciente terminal, maior o desenvolvimento de raciocínio das enfermeiras para justificar sua morte; na teoria formal a hipótese seria: (a) quanto maior o valor social de uma pessoa, menor será o atraso que experimentará para receber os serviços de especialistas (Ibid).

\section{Considerações adicionais sobre o método}

De acordo com os postulados da Teoria Fundamentada nos Dados, a coleta dos dados paralelamente à sua codificação ocorre até a saturação teórica. $\mathrm{Na}$ prática, limitações de prazo e de recursos comumente associados ao desenvolvimento de projetos de pesquisa conferem à saturação teórica uma dimensão utópica (BANDEIRADE-MELLO e CUNHA, 2007). Mesmo tratando-se de um projeto acadêmico, há demandas a cumprir e prazos a serem obedecidos, o que mantém a pressão acerca de prazos e resultados.

A realização de uma pesquisa de tendências é complexa e absorvente. Os insights podem surgir a qualquer momento e os erros são comuns à rotina dos iniciantes. Durante o processo de realização de pesquisa, deve-se sempre focar na coesão e na lógica em relação à realidade dos acontecimentos observados e analisados. Lembrando sempre de que há várias maneiras de se observar a realidade, portanto, várias realidades. Em concordância com Charmaz (2000), Bandeira-de-Mello e Cunha (2007) reiteram que o pesquisador compõe a história que analisa; portanto a delimitação da teoria reflete não apenas os observados, mas também o observador.

A teoria não emerge simplesmente dos dados, mas do intercâmbio do pesquisador com esses dados, por mais que o método - em teoria - crie um distanciamento entre pesquisador e objeto. Uma boa teoria - de tendência, acrescenta-se - deve ser clara na representação da visão expostas pelos sujeitos estudados; logo, o método da pesquisa precisa ser detalhado e atender a demanda de comparação constante.

No contexto do FPLab, a codificação aberta é revisada por todos os integrantes da equipe de pesquisa. Neste mesmo momento, em reuniões que ocorrem 
semanalmente, também acontecem as etapas de codificação axial e seletiva e, de acordo com os prazos estabelecidos na fase de planejamento, a delimitação das tendências divididas em áreas de influência. É importante frisar que, no decorrer do tempo, aumenta a experiência dos participantes do projeto enquanto pesquisadores de tendências, o que minimiza falhas e conduz à trajetória de no campo da pesquisa.

\section{Considerações finais}

O presente estudo pretendeu apresentar de modo revisado o método de pesquisa de tendências desenvolvido e aplicado pelo FPLab -Futuro do Presente. O projeto atua continuamente na pesquisa de tendências e no desenvolvimento de diretrizes de orientação para produtos e serviços nas áreas de moda e design. O escopo e objetivo do projeto mostram-se relevantes e atualizados, uma vez que é crescente o interesse pelas tendências de moda e de comportamento.

O conhecimento sobre as tendências é muito valorizado na atualidade, pois apesar de viver-se em contexto de amplo e livre acesso às informações, o processo de interpretação dessas informações é a atividade desafiadora a ser conduzida. Recorreu-se à Sociologia e às Ciências Sociais e Humanas para propor um modelo conceitual relevante para a pesquisa prospectiva, buscando agregar conhecimento acerca de procedimentos e instrumentos de observação e análise que permitem uma compreensão do contemporâneo.

Ao desenvolver-se um método a ser aplicado - inicialmente proposto como modelo conceitual (CAMPOS, 2010) - considerou-se a centralidade do exercício interpretativo, enfocando as etapas de codificação. A base teórica e metodológica da Teoria Fundamentada nos Dados igualmente atende à demanda da pesquisa de tendências que implica em "ir a campo" sem hipóteses ou problemas de pesquisa definidos ou imutáveis. A teoria que deriva dos dados, assim, possibilita que a coleta de dados forneça pistas de tendências que, no decorrer da pesquisa, serão investigadas, reforçadas, reformuladas ou definidas (delimitadas).

O método desenvolvido enfoca a compreensão de contextos transversais e objetiva o entendimento das diversas influências (comportamento, macrotendências e setores de referência) para que as incertezas em relação à posteridade sejam minimizadas. A proposta teve como foco o projeto acadêmico de pesquisa do 
Departamento de Moda da Universidade do Estado de Santa Catarina, todavia, pode ser aplicada por outras universidade e empresas de outros setores, sendo realizados ajustes requeridos. Por fim, considera-se que, assim como este artigo já desenvolve alguns ajustes sobre o modelo conceitual desenvolvido nos anos de 2009-2010 e com a continuidade do projeto FPLab, é intuito destas autoras que este método seja revisado, alterado, aperfeiçoado; respondendo ele mesmo a tendências latentes na prática de pesquisa de tendências.

Artigo recebido em Julho de 2015. Aprovado em Setembro de 2015
DOI:http://dx.doi.org/105965/1982615x08172016027

\section{Referências}

BACK, Suzana. Pesquisa de Tendências - um modelo de referência para pesquisa prospectiva. 2008. 138f. Dissertação (Mestrado em Engenharia de Produção) Programa de Pós-Graduação em Engenharia de Produção, UFSC, Florianópolis.

BANDEIRA-DE-MELLO, Rodrigo; CUNHA. Grounded Theory. In: GODOI, Christiane; BANDEIRA-DE-MELLO, Rodrigo; SILVA, Anielson. Pesquisa Qualitativa em Estudos Organizacionais: Paradigmas, Estratégias e Métodos, 2006. pp. $241-266$

BARCARO, Andrea. Os processos de uma empresa de moda. In: SORCINELLI, Paolo (org.). Estudar a Moda: corpos, vestuários, estratégias. São Paulo: Editora SENAC, 2008, pp. $143-156$.

CALDAS, Dário. Observatório de sinais: teoria e prática da pesquisa de tendências. Rio de Janeiro: Senac Rio, 2004. 
CAMPOS, Amanda Queiroz. Prognósticos do porvir: Desenvolvimento de Metodologia Conceitual para Pesquisa Prospectiva. 2010. Trabalho de Conclusão de Curso (Bacharelado em Moda com Habilitação em Estilismo) - Programa de Graduação em Moda, UDESC, Florianópolis.

O mito como incremento do produto na gestão da marca de moda: estudo de imagens gráfico publicitárias das marcas Lança Perfume e Morena Rosa. 2013. 171f.Dissertação (Mestrado) - Programa de Pós-Graduação em Design e Expressão Gráfica da Universidade Federal de Santa Catarina. Florianópolis, 2013.

CAMPOS, Amanda Queiroz; PERASSI, Richard Luiz de Sousa; RECH, Sandra Regina. Por uma abordagem qualitativa dos dados: A pesquisa de tendências embasada na Grounded Theory. Modapalavra E-periódico, v. 5, p. 47-70, 2012

CAMPOS, Amanda Queiroz; RECH, Sandra Regina. The Future of the Present: Why \& How of research trends. Multi: The Journal of Plurality and Diversity in Design, v. 03, p. 35-47, 2010.

CASSIANI, Silvia Helena De Bortoli; CALIRI, Maria Helena Larcher; PELÁ, Nilza Teresa Rotter. A teoria fundamentada nos dados como abordagem da pesquisa interpretativa. Rev. latino-am. enfermagem - Ribeirão Preto - v. 4 - n. 3 - p. 75-88 dezembro 1996.

CHARMAZ, Kathy. A Construção da Teoria Fundamentada: guia prático para análise qualitativa. Porto Alegre: Artmed, 2009.

CORBIN, Juliet; STRAUSS, Anselm. Basics of qualitative research: techniques and procedures for developing Grounded Theory. 3a edição. Londres: Sage Publications, 2008).

DAWKINS, Richard. O gene egoísta. Compania das Letras: São Paulo, 2007.

GLADWELL, Malcolm. O ponto da virada: the tipping point. Rio de Janeiro: Sextante, 2009. 
GLASER, Barney; STRAUSS, Anselm. The discovery of Grounded Theory: strategies for qualitative research. Chicago: Aldine Transaction, 1967.

KELLEY, Tom,; LITTMAN, Jonathan,. A arte da inovação: lições de criatividade da IDE0, a maior empresa norte-americana de design. São Paulo: Futura, 2001.

MANN, Peter. Métodos de Investigação Sociológica. 4a edição. Rio de Janeiro: Zahar Editores: 1979.

MORACE, Francesco (org). Consumo autoral: as gerações como empresas criativas; tradução: Kathia Castilho. São Paulo: Estação das Letras e Cores Editora, 2009.

LINDKVIST, Magnus. O guia do caçador de tendências: como identificar as forças invisíveis que moldam os negócios, a sociedade e a vida. São Paulo: Editora Gente, 2010.

McCRACKEN, Grant. Chief culture officer: como a cultura pode determinar o sucesso ou fracasso de uma organização. São Paulo: Aleph, 2011.

MONÇORES, Aline. Tendências: o novo constante. 2013. 177f. Tese (Doutorado). Programa de Pós-Graduação em Design Departamento de Artes e Design da Pontifícia Universidade Católica do Rio de Janeiro, Rio de Janeiro, 2013a.

PANDIT, Naresh R. The Creation of Theory: a recente application of the Grounded Theory Method. The Qualitative Report, Volume 2, Number 4, December, 1996. PETERMANN, Elisabeth. Archeology of the Future. Reconsidering the place and nature of trend forecasting in design discourse. Edited by DRS 2014. Umea University of Design, 2014. Disponível em: <http://www.drs2014.org/media/654126/0164-file1.pdf>. Acesso em: 09 de junho de 2015. 
RAYMOND, Martin. Tendencias: que son, cómo identificarlas, en qué fijarnos, cómo leerlas. London: Promopress, 2010.

RECH, Sandra Regina. Estudos do Futuro \& Moda: uma abordagem conceitual. Modapalavra E-periódico, v. 12, p. 1-18, 2013.

RECH, Sandra Regina; MACIEL, Dulce Maria Holanda. A Proposal for Prospective Method based on Grounded Theory. In: The Value of Design Research - 11th International European Aacademy of Design Conference, 2015, Paris - França. The Value of Design Research. Paris: European Aacademy of Design, 2015.

RIEZU, Marta Dominguez. Coolhunting: marcando tendencias en la moda. Barcelona: Parramón Arquitectura y Diseño, 2009.

SANTOS, Janiene. Sobre tendências e o espírito do tempo. São Paulo: Estação das Letras e Cores, 2013.

SONEIRA, Abelardo Jorge. La "Teoria fundamentada em los datos" (Grounded Theory) de Glaser y Strauss. In: GIALDINO, Irene (coord). Estrategias de investigación cualitativa. Buenos Aires: Gedisa Editoral, 2007. pp. 153 - 173.

STRAUSS, Anselm. Qualitative analysis for social scientists. Cambridge: Cambridge University Press, 1987.

UERZ, Georg. ÜberMorgen: Zukunftsvorstellungen als Elemente der gesellschaftlichen Konstruktion der Wirklichkeit. München: Wilhelm Fink, 2008. VAN DER DUIN, Patrick. (Ed.). Knowing Tomorrow? How Science Deals With the Future. Eburon Uitgeverij B.V, 2007.

VEJLGAARD, H. Anatomy of a trend. New York: McGraw-Hill, 2008. 
VICENTINI, Claudia Garcia; CASTILHO, Kathia. O corte, a costura, o processo e o projeto de moda no re-design do corpo. In: OLIVEIRA, Ana Cláudia de; CASTILHO, Kathia (org). Corpo e Moda: por uma compreensão do contemporâneo. pp. 125 - 135.

VICENT-RICARD, Françoise. As espirais da moda. Rio de Janeiro: Paz e Terra, 2008. 